\title{
Free-Air Gravity Map of Taiwan and Its Applications
}

\author{
Horng-Yuan Yen, Yhi-Hsiung Yeh, Cheng-Horng Lin \\ Institute of Earth Sciences \\ Academia Sinica, Taipei, Taiwan, R.O.C. \\ GUEY-KUEN YU \\ Institute of Geophysics \\ National Central University, Chang-Li, Taiwan, R.O.C. \\ AND \\ YI-BEN TSAI \\ 481 Patrick Way, Los Allos, CA 94022, U.S.A.
}

(Received 19 April 1990; revised 25 June 1990)

\begin{abstract}
An island-wide gravity survey in Taiwan was conducted by the Institute of Earth Sciences, Academia Sinica, between 1980 and 1987. The 603 stations at which the gravity values were determined included 308 points in the $500 \mathrm{~m}$ or higher mountain range where few readings were available previously. The average spacing of the stations in the present survey is about $7 \mathrm{~km}$ apart. A new Free-air gravity anomaly map has been constructed based on these values. The map is dominated by a NNE-SSW gravity high trend with a maximum value of $300 \mathrm{mgal}$, that follows closely the Central Range, a folded and faulted mountain belt with many peaks $3000 \mathrm{~m}$ or higher. The magnitude of the Free-air anomaly in the Taiwan area is quite large compared to that elsewhere in the world. The good correlation between the Free-air anomaly and elevation suggests that the Taiwan area is not in isostatic equilibrium. An average surface rock density of $2.57 \mathrm{~g} \mathrm{~cm}^{-3}$ is estimated from the Free-air gravity data by using the least-squares method. This value can be used for both terrain and Bouguer corrections. The undulation of the geoid and the deflections of the vertical in the Taiwan area are also calculated by using the Free-air anomaly data. The geoid undulation is not rugged over the Taiwan area. The maximum difference is about $5 \mathrm{~m}$. And the deflection of the vertical seems mainly to be affected by both land and submarine topographies.
\end{abstract}

\section{INTRODUCTION}

As shown in the topographic map (Fig. 1) which is prepared by the authors, (the map is essentially made from 1:50000 scale topographic maps by a 
digitizing procedure with a $1 \mathrm{~km}$ grid size), large parts of Taiwan are occupied by mountainous areas. In the mountain ranges, there were very few available gravity data (Chang and $\mathrm{Hu}, 1981$ ). In order to have complete gravity data for the Taiwan area, a comprehensive gravity survey, especially in the mountain ranges, has been conducted by the Institute of Earth Sciences, Academia Sinica from 1980 to 1987 . Gravity measurements had been done mainly at geodetic stations. In this study, a new Free-air gravity anomaly map has been constructed. Its tectonic implications are also discussed. In addition, an average surface rock density, the undulation of the geoid and the deflections of the vertical for the Taiwan area are also estimated by using these data.

\section{GRAVITY SURVEY}

A LaCoste-Romberg Model D-47 microgal gravimeter was used for the islandwide gravity survey in Taiwan in this study. This meter has a range of $200 \mathrm{mgal}$ with a reset for worldwide operations, and a reading accuracy of $5 \mu \mathrm{gal}$. Its instrumental drift is about $450 \mu \mathrm{gal}$ per month and can be considered as a linear function of time (Yeh et al., 1982). Since between two stations in the field, the meter was clamped, the drift effect can be neglected for the island-wide survey. From the study on the tidal variation of gravity in Taiwan done by Yeh et al. (1982), we found that the maximum amplitude of the tidal effect in Taiwan is about $0.4 \mathrm{mgal}$. This magnitude is less than the accuracy we expected. Thus, the tidal effect is also neglected in our work.

The reference base gravity station we used is at the Taipei Military Air Transport Service Terminal (TMATST). Its absolute gravity value is 978959.15 mgal which is tied to the International Gravity Standardization Net 1971 (IGSN 71). For the convenience of measurements, we selected seven suitable subbase stations throughout the Taiwan area which were established by Yeh et al. (1979). All these sub-base stations are tied to the TMATST base station. The locations of base and sub-base stations are shown in Fig. 2. Gravity measurements were made at benchmarks of the first order levelling network, at triangulation points and at spot heights which are shown on 1:10000 scale topographic maps. In this case, we can save the labor of determining the locations and elevations of stations. In the field, we did not use the traditional chainloops procedure which can be used for the drift and tidal corrections. In order to have the measurement reliability, a closed-loop method was adopted. This means that in a survey area, at least two measurements were made at a certain sub-base station at different times. If the variation of these two measurements were less than $0.5 \mathrm{mgal}$, all measuremants within this loop were considered to be acceptable. In total, 603 gravity stations had been established over the Taiwan area (as shown in Fig. 2). Among them, 308 stations were located in 


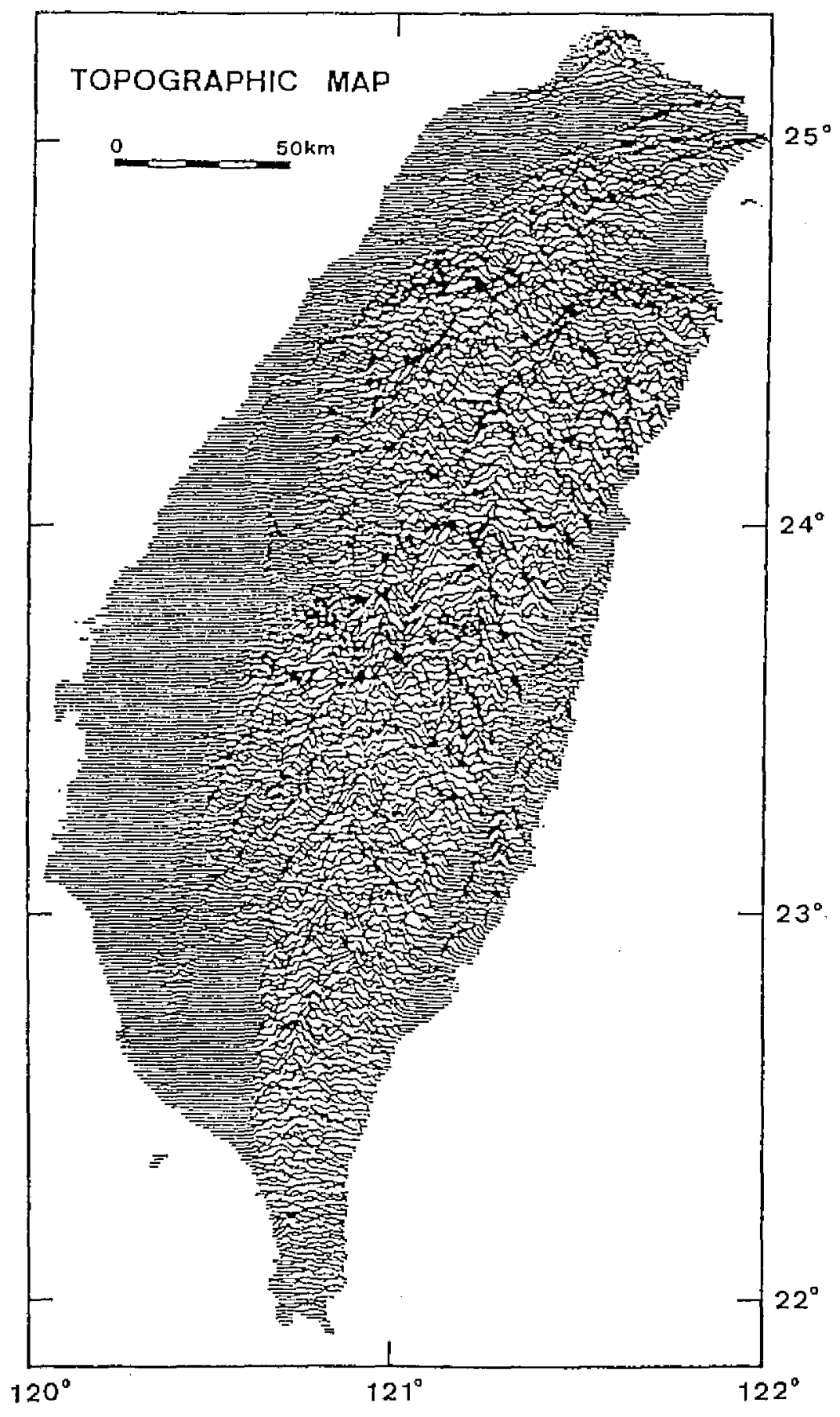

Fig. 1. Topographic map of Taiwan.

the $500 \mathrm{~m}$ or higher where few readings were available previously. The average spacing between the stations is about $7 \mathrm{~km}$. 


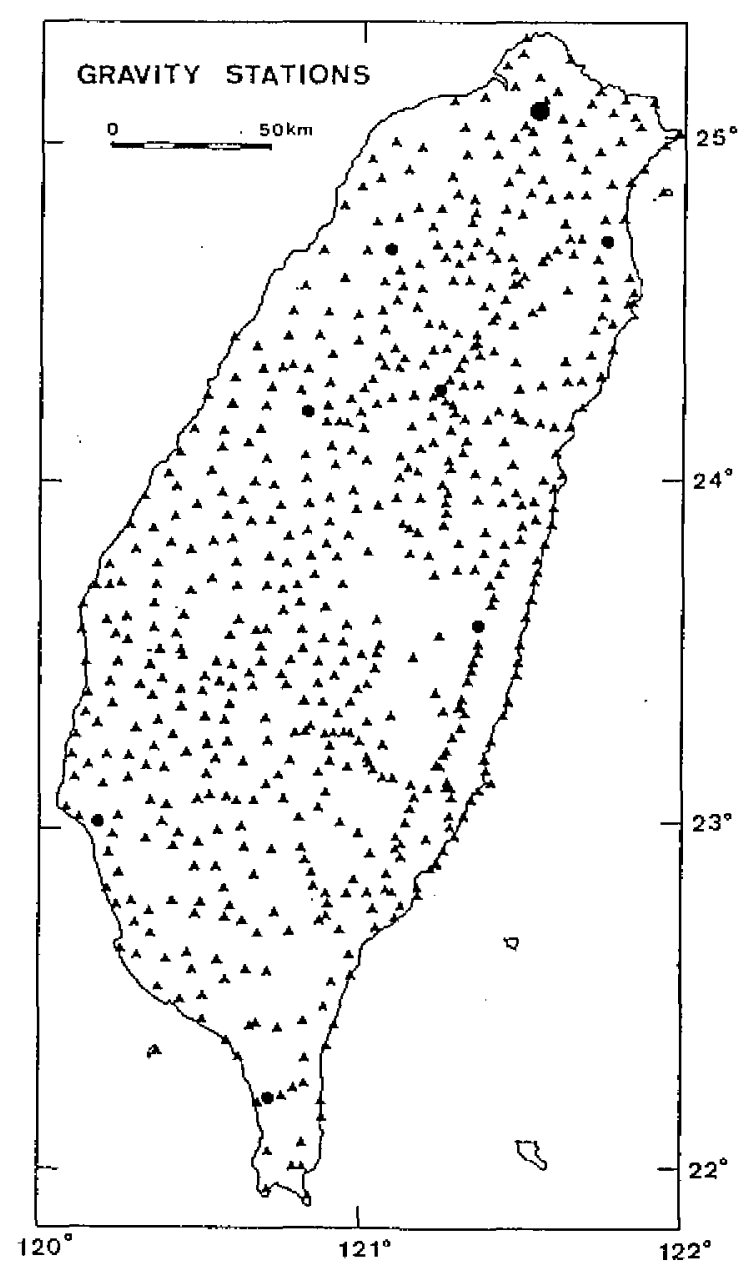

Fig. 2. Gravity stations in Taiwan ( $\bullet$ TMATST base-station; * : sub-base stations).

\section{FREE-AIR GRAVITY ANOMALY}

In order to obtain the Free-air anomaly, corrections of latitude and Free-air are made. The latitude correction is based on the theoretical gravity formula of GRS-67, which is

$$
G=978031.85\left(1+0.005278895 \sin ^{2} \phi+0.000023467 \sin ^{4} \phi\right) m g a l,
$$

where $\phi$ is the geographic latitude of the gravity station. For simplicity, the vertical gravity gradient of $0.3086 \mathrm{mgal} \mathrm{m}^{-1}$ is used for Free-air correction anywhere on the earth surface. However, the vertical gravity gradient is correlated with topography and latitude (Hagiwara, 1967). Since a large number of gravity stations in Taiwan are in mountainous areas, it is clear that this vertical 
gradient is not appropriate for this study. For obtaining sufficient accuracy, the Free-air correction $\Delta g$ is taken as

$$
\Delta g=2 G(h / r)[1-3(h / r) / 2+\ldots .] \quad \text { (Dehlinger, 1978), }
$$

where $G$ is the theoretical gravity value at sea level on a spherical earth, $r$ is the radius of the earth and $h$ is the elevation of station. The second term of equation (2) can not be neglected for stations at higher elevations. In practice, gravity data are reduced to the surface of the geoid. The radius of the geoid $(r)$ at the station can be obtained by using the equation

$$
r=a\left[1+\left(2 f-f^{2}\right) \sin 2 \phi /(1-f)^{2}\right]^{-\frac{1}{2}}
$$

(Heiskanen and Vening-Meinesz, 1958),

where $a$ is the equatorial radius and $f$ is the flattening. In this study, $a$ of $6378139 \mathrm{~m}$ and $f$ of $1 / 298.256$ are used for defining a reference geoid. Based on equations (2) and (3), the average vertical gradient at sea level in the Taiwan area is about $0: 3071 \mathrm{mgal} \mathrm{m}^{-1}$. After reductions of latitude and Free-air, the Free-air gravity anomalies are obtained. The magnitude of the anomaly in the Taiwan area is quite large compared to that anywhere else in the world. Their contour map is shown in Fig. 3. This map indicates that the Freeair anomaly largely mimics topography. A high gradient contour is shown in the mountain area. A conspicuous gravity high, trending NNE-SSW with a maximum value of $300 \mathrm{mgal}$, extends along the Central Range from Ilan through Lishan, Hsiukuluanshan and Kuanshan to Peitawushan. An anomaly high in the Hsueshan Range is also shown. The maximum value is up to 275 mgal. Three gravity lows are located in the Western Coastal Plain, the Ilan Plain and the Pingtung Plain respectively. Obviously, these lows are associated with thick sediments.

One can think of the Free-air anomaly as retaining all the mass of topography by reducing it to a density film at sea level. If a Free-air anomaly is small over a large topographic high, there must be a mass deficiency at depth to compensate for the mass excess that forms the topography at the surface. In other words, highly positive Free-air anomalies are generally found over topographic highs which are not locally compensated (Verma, 1985). Consequently, the existence of strong correlation between the Free-air anomaly and elevation suggests that the Taiwan area is not in isostatic equilibrium. The study of this isostasy problem is being undertaken by the authors.

\section{SURFACE ROCK DENSITY}

It is important to estimate an appropriate average density of surface rocks for both terrain and Bouguer corrections. Usually, this estimation is not easy 


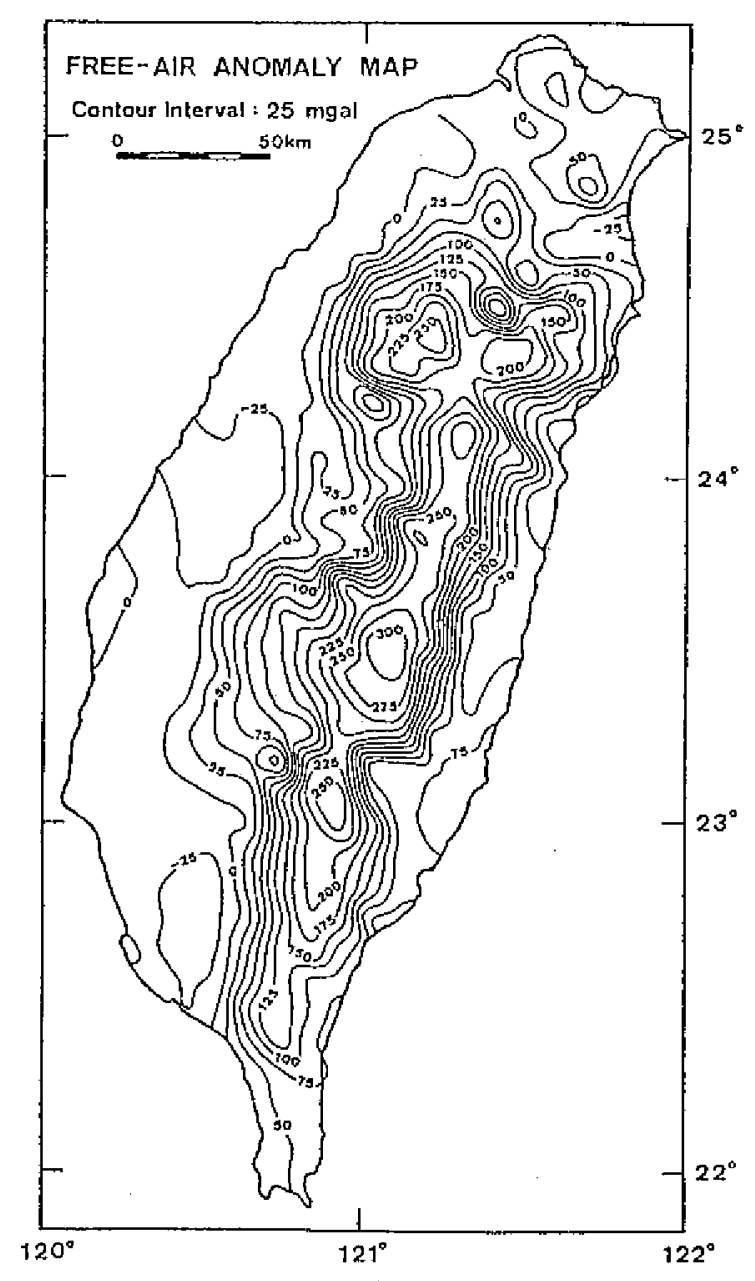

Fig. 3. Free-air gravity anomaly map of Taiwan (contour interval: $25 \mathrm{mgal}$ ),

to make. A good method to estimate the density based on the real gravity data has been developed by Fukao et al. (1981). The basic concept of this method is to find a density which may minimize the correlation of the Bouguer anomaly with the topography. This concept is similar to that of the Nettleton's method (1939) which is used for a profile gravity data. In this study, the Fukao et al. method is used for determining an average density of surface rocks over the Taiwan area. This method is described briefly as follows.

A Bouguer anomaly value $B(\rho)$ is determined for a certain density $\rho$ by

$$
B(\rho)=F-H \times \rho,
$$

where $F$ is the Free-air anomaly and $H$ is the topographic factor. This factor is defined as the difference between the Bouguer and terrain corrections, assuming $\rho$ equals $1 \mathrm{~g} \mathrm{~cm}^{-3}$. In this method, the survey area is divided into meshes of 
equal size in order to get a set of mesh-averaged Bouguer anomalies $\bar{B}_{j}(j=$ $1,2, \ldots, J)$. An optimum average density of $\rho_{0}$ and a set of $\bar{B}_{j}$ can be obtained by minimizing in a least-squares sense of the difference between $B(\rho)$ and $\bar{B}_{j}$. That is

$$
\sum_{j=1}^{J} \sum_{k=1}^{K_{j}}\left[B_{j k}(\rho)-\bar{B}_{j}\right]^{2} \longrightarrow \text { MINIMUM, }
$$

where $B_{j k}(\rho)=F_{j k}-H_{j k} \times \rho$ is the value of $B(\rho)$ at the $k$-th observation point $\left(k=1,2, \ldots \ldots, K_{j}\right)$ in the $j$-th mesh. $K_{j}$ is the total of the observation points in the $j$-th mesh. The average density can be calculated by the equation as

$$
\begin{gathered}
\rho_{0}=\frac{\sum_{j=1}^{J} \sum_{k=1}^{K_{j}}\left(F_{j k}-\bar{F}_{j}\right)\left(H_{j k}-\bar{H}_{j}\right)}{\sum_{j=1}^{J} \sum_{k=1}^{K_{j}}\left(H_{j k}-\bar{H}_{j}\right)^{2}}, \\
\bar{B}_{j}=\bar{F}_{j}-\bar{H}_{j} \times \rho_{o},
\end{gathered}
$$

where

$$
\bar{F}_{j}=\sum_{k=1}^{K_{j}} F_{j k} / K_{j}, \quad \bar{H}_{j}=\sum_{k=1}^{K_{j}} H_{j k} / K_{j},
$$

The density so estimated is in general dependent on the mesh size. A larger mesh size is associated with a lower estimate of density and vice versa.

In this study, the mesh sizes are given from $1^{\prime} \times 1^{\prime}$ to $210^{\prime} \times 210^{\prime}$. The density is calculated as a function of the mesh size according to equation (6), in which the meshes with less than two data points are excluded. Fig. 4 is a plot of the set of estimated densities as a function of different mesh sizes in the semilog chart. The densities for the mesh sizes from 1' $\times 1$ ' to $10^{\prime} \times 10^{\prime}$ show an approximately constant value of $2.57 \mathrm{~g} \mathrm{~cm}^{-3}$. This constancy indicates that the Bouguer anomaly is least correlated with topography in a mesh dimension of less than $10^{\prime} \times 10^{\prime}$. Thus, it may be concluded that an optimum average density of $2.57 \mathrm{~g} \mathrm{~cm}^{-3}$ is obtained for surface rocks in the Taiwan area. This average density can be used for both terrain and Bouguer corrections to obtain complete Bouguer anomalies.

\section{GEOID UNDULATION AND DEFLECTION OF THE VERTICAL}

The geoid is an equipotential surface which, for a first approximation, is represented by the mean sea level. Irregular mass distributions in the earth, particularly in the outer layers, will affect the shape of the geoid. It is known that the geoid is warped upward under the continental mass due to attracting material above and downward over the ocean basin. Clearly, for most practical purposes the equipotential surface of earth's gravity field is the geoid which 


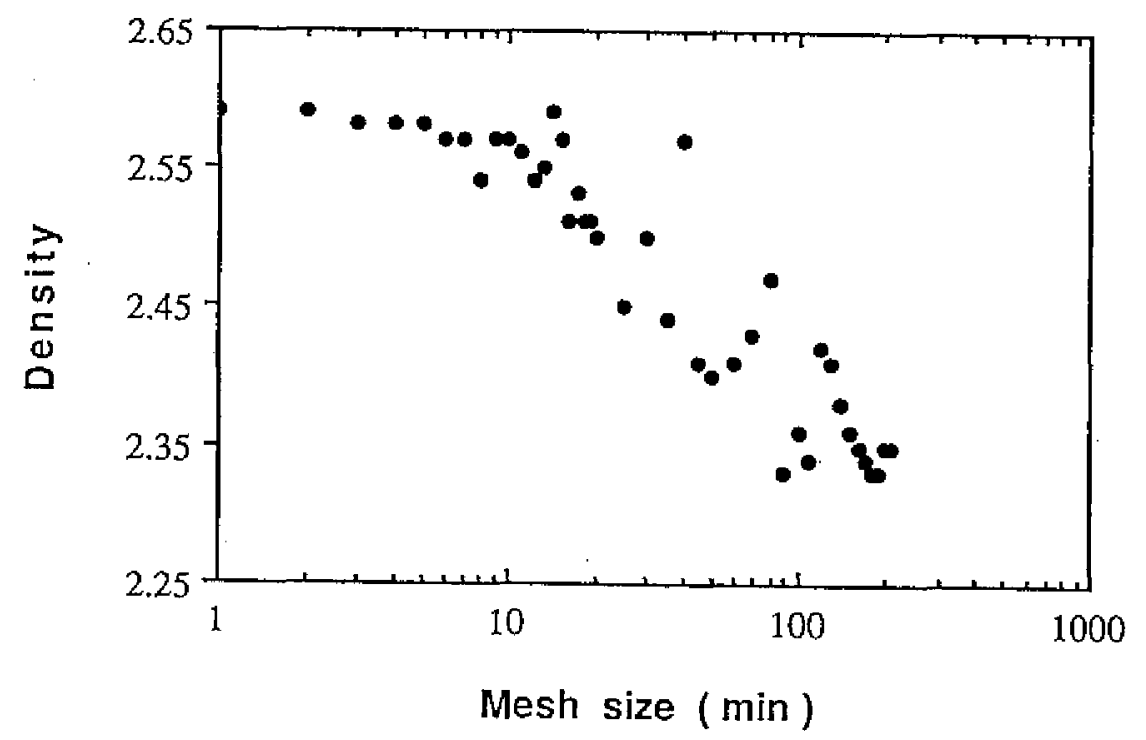

Fig. 4. Plot of optimum density as a function of mesh size. The mesh sizes are from 1' $\times 1$ ' to 210 ' $\times 210$ '. This plot indicates an optimum average density of surface rocks in Taiwan area is about $2.57 \mathrm{~g} \mathrm{~cm}^{-3}$.

lies close to the spheroid but does not exactly coincide with it. In fact, the irregular geoid shape cannot readily be described mathematically. However the general shape of the geoid can be estimated by using Stoke's theorem (1849). For simplicity the shape of the geoid is described by the height of its undulation from the spheroid. The geoid height $\mathrm{N}$ relative to the Free-air anomaly $\Delta g$ of a surface element $d \sigma$ can be expressed by the equation,

$$
N=\frac{1}{4 \pi g R} \int_{0}^{A} S(\Psi) \Delta g d \sigma
$$

(Heiskanen and Vening-Meinesz, 1958)

where $R$ is the mean radius of the earth, $g$ is the mean gravity value of the earth, $A$ is the surface area of the sphere with its mean radius, and $\Psi$ is the angular distance of $d \sigma$ from a calculated point. $S(\Psi)$ is a function of the interior angle between the radius vectors to the point where $N$ is determined and the elements on the geoid with an anomaly $\Delta g . S(\Psi)$ is given by

$$
\begin{aligned}
S(\Psi)= & c s c(\Psi / 2)+1-5 \cos \Psi-6 \sin (\Psi / 2) \\
& -3 \cos \Psi \ln [\sin (\Psi / 2)(1+\sin (\Psi / 2))]
\end{aligned}
$$

The value of $S(\Psi)$ is small at large distances from where $N$ is determined. Accordingly, distant anomaly bodies have only slight effects on the value of $N$.

We calculate the average geoid heights in the Taiwan area by using different angular distances from $20^{\prime}$ to $180^{\prime}$ with an increment of $10^{\prime}$. Fig. 5 shows 
the differences of the average geoid heights between each of two neighboring angular distances. It is noted from this figure that the difference of the average geoid heights is about $0.1 \mathrm{~m}$ when the angular distance is from 2 to 3 degrees. Thus, an angular distance of 3 degrees is assumed to be used for calculation in this study. In this case, gravity data in the area between $18.5^{\circ}$ to $28.5^{\circ} \mathrm{N}$ and $117^{\circ}$ to $125^{\circ} \mathrm{E}$, which includes the island of Taiwan and its offshore territory, are needed. Data of the land areas are shown in Fig. 3. Data of the offshore areas are mainly taken from the compilation of Bowin et al. (1981).

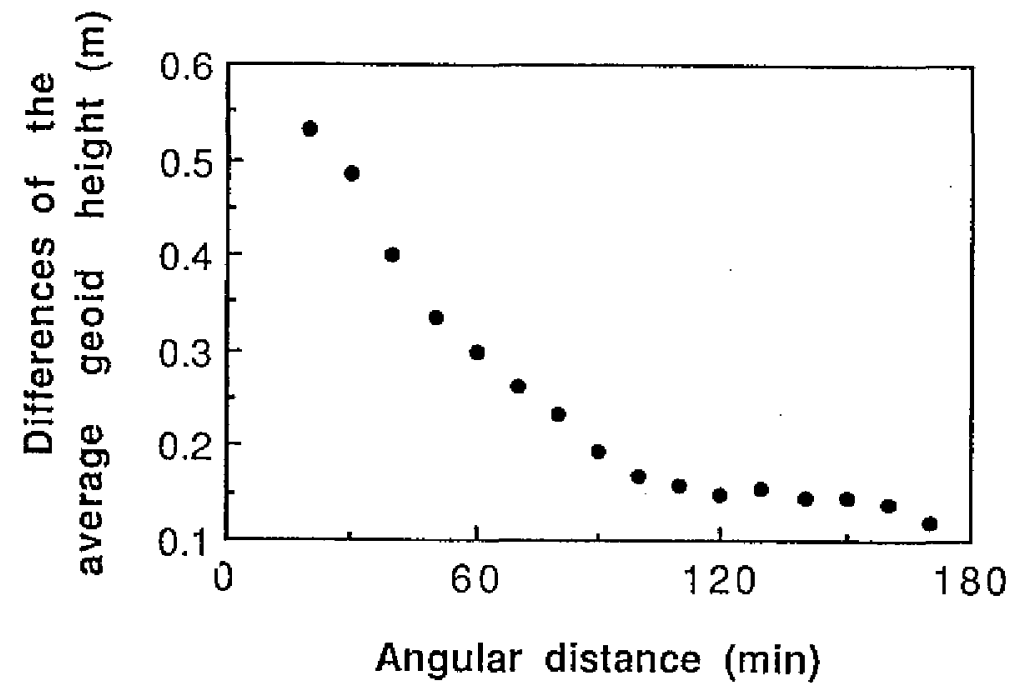

Fig. 5. Differences of average geoid heights between each of two neighbor angular distances. The increment of angular distance is 10 '.

It is hard to derive the absolute value of the geoid height by using only local gravity data. So, only relative undulations are estimated in this study. The mean Free-air anomaly value is taken for $10^{\prime} \times 10^{\prime}$ in this calculation. The equatorial radius $6378139 \mathrm{~m}$ and the average absolute gravity value 978854.7 mgal for the Taiwan area are used. The result of the geoid undulation is shown in Fig. 6. The geoid height is generally positive in the Taiwan area except in the Hungchun Peninsula. A maximum value of $4 \mathrm{~m}$ is found located in Nantou County, the middle part of the Taiwan Island. The shape of the geoid is convex there. The geoid height on the island of Taiwan is higher than those of its surrounding ocean areas. This fact indicates that the geoid heaves up above the excess crust that forms the island-arc. The geoid height which decreases to the east and the south of the island may be caused by mass deficiencies due to deeper bathymetry and by relatively low density materials beneath these areas. Usually the Free-air reduction is done to the sea level, however, rigorous Freeair reduction should be made further for the departure of the geoid from the 
spheroid. Since the geoid undulation in and around Taiwan is not conspicuous and the maximum magnitude of the difference is only about $5 \mathrm{~m}$, this rigorous reduction may be not necessary to deal with.

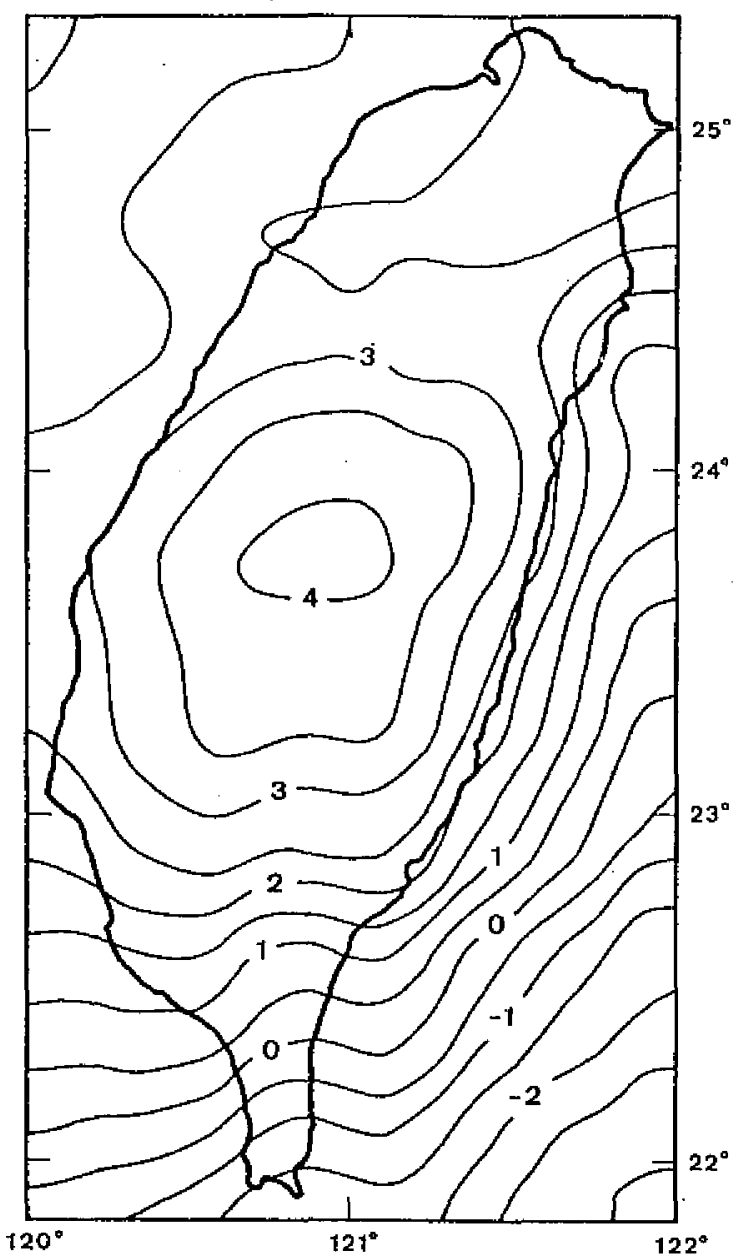

Fig. 6. Geoid undulation map of Taiwan and its surrounding region (contour interval: $0.5 \mathrm{~m}$ ).

The deflection of the vertical is an angle between the normals to the geoid and spheroid at a point on the geoid. It is necessary to know this deflection for precise astronomical and geodetic measurements. The deflection of the vertical is the slope of the geoid (i.e. the gradient of $N$ ), usually expressed by its north and east components. They can be obtained from equation (9) as the derivatives of the geoid height in the vertical plane in NS and EW directions. Fig. 7 is a map of the deflection vectors in the Taiwan area as determined in this study. Smaller deflections are found along the middle part of the Central 
Range. The deflection vectors seem to be directed radially. In the offshore area, the deflections in the east and the south are larger than those in the west and the north. It may be concluded that the deflection of the vertical in Taiwan area is mainly affected by both land ands submarine topographys.

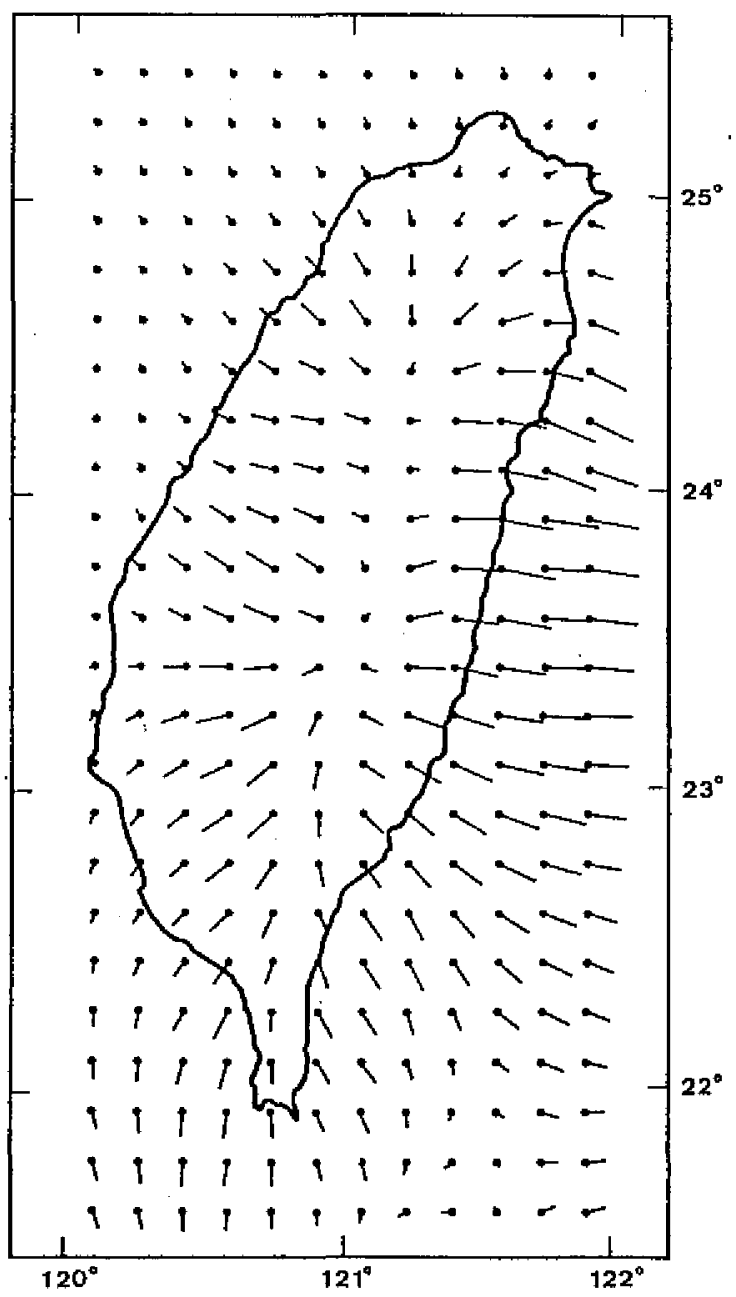

Fig. 7. Deflections of the vertical of Taiwan $\left(-: 25^{\prime \prime}\right)$.

\section{CONCLUSIONS}

A new Free-air anomaly map of Taiwan is constructed in this study based on recent gravity data. The magnitude of the Free-air anomaly is quite large compared to that elsewhere in the world. The good correlation between Free-air anomaly and elevation suggests that the Taiwan area is not in isostatic equilibrium. An average density in the Taiwan area is $2.57 \mathrm{~g} \mathrm{~cm}^{-3}$ for surface rocks. 
The geoid undulations are not rugged over the Taiwan area. The maximum difference is about $5 \mathrm{~m}$. Thus it is not necessary to consider the undulation in the free-air reduction. The deflection of the vertical in Taiwan area seems to be affected mainly by the topographies of both land and submarine.

Acknowledgements. Thanks for all who joined the field work of in the past few years. The authors are grateful to Mr. S. N. Cheng and Miss H. F. Chiu for drafting the figures. This study is sponsored by the Institute of Earth Sciences, Academia Sinica, and the National Science Council, Republic of China.

\section{REFERENCES}

Bowin, C., W. Warsi, and J. Milligan, 1982: Free-air gravity anomaly atlas of the world: Geological Society of America Map and Chart Series, No. $\mathrm{MC}-46$.

Chang, Stanley S. L. and C. C. Hu, 1981: Gravity and magnetic anomalies of Taiwan and their tectonic implication. Mem. Geol. Soc. China, no. 4, 121-142.

Dehlinger, P., 1978: Marine gravity, Elsevier Scientific Publishing Co., Netherlands, 322pp.

Fuako, Y., A. Yamamoto and K. Nozaki, 1981: A method of density determination for gravity correction. J. Phys. Earth, 29, 163-166.

Hagiwara, Y., 1967: Analyses of gravity values in Japan. Bull. Earthq. Res. Inst., 45, 1091-1228.

Haiskanen, W. A., and F. A. Vening Meinesz, 1958: The earth and its gravity field, McGraw-Hill Book Co., New York, 159-161.

Nettleton, L. L., 1939: Determination of density for reduction of gravimeter observations. Geophysics, 4, 176-183.

Stokes, G. G., 1849: On the variation of gravity at the surface of earth. Trans. Cambridge Phil. Soc., 8, 672 .

Verma, R. K., 1985: Gravity field, seismicity and tectonics of the Indian Peninsula and the Himalayas. D. Reidel Publishing Co., Dordrecht, Holland, 213pp.

Yeh, Y. H., S. K. Huang, Y. H. Tzou, Y. B. Tsai, and Y. H. Wu, 1979: Repeat gravity measurements in Taiwan. Open File Report, Inst. Earth Sci., Academia Sinica, 198pp. (in Chinese).

Yeh, Y. H., Y. B. Tsai and M. C. Wang, 1982: A study of tidal variation of gravity in northern Taiwan. Bull. Inst. Earth Sci., Academia.Sinica, 2, $75-90$. 


\title{
台灣自由空間重力圖及其應用
}

\author{
顔宏元 葉義雄 林正洪 \\ 中央硏究院地球科學䂰究所 \\ 余貴坤 \\ 國立中央大學地球物理硏究所 \\ 蔡義本 \\ 美國太平洋瓦斯及電力公司
}

摘 要

中央研究院地球科學研究所於民國六十九年至七十六年間, 進行全省性之重力測量, 共 完成 603 個重力觀測站, 其中有 308 個溂站是分布在重力資料較缺乏的山區，測站間的平均 距離䄪爲七公里。根璩這些賽測重力資料繪製出台灣地區新的自由空間異常圖, 在嗄圖中有 一沿荖中央山脈, 呈北北東一南南西走向的重力泊區, 其異常値高達 300 毫伽。由地形與自 由空間哄常的關係可明顯看出, 台簒地區向未達到均衡狀態。利用最小二乘法, 由重力資粹 估算出台潛地區地表岩層平均密度爲 2.57 公克 /立方公分, 此平均密度可供地形及布蓋修 正使用。本文亦利用重力異常資料求取大地起伏及垂線偏差, 結果顯示台灣地區之大地起伏 平緩，起伏的差值約矞五公尺；垂線偏差主要是受陸上及海底地形所影響。 
Vol.1, No.2 